IZA DP No. 9675

Tattoos, Life Style and the Labor Market

Rik Dillingh

Peter Kooreman

Jan Potters

January 2016

Forschungsinstitut zur Zukunft der Arbeit Institute for the Study of Labor 


\title{
Tattoos, Life Style and the Labor Market
}

\author{
Rik Dillingh \\ Tilburg University \\ Peter Kooreman \\ Tilburg University \\ and IZA \\ Jan Potters \\ Tilburg University
}
Discussion Paper No. 9675
January 2016

\author{
IZA \\ P.O. Box 7240 \\ 53072 Bonn \\ Germany
}

Phone: +49-228-3894-0
Fax: +49-228-3894-180
E-mail: iza@iza.org

Any opinions expressed here are those of the author(s) and not those of IZA. Research published in this series may include views on policy, but the institute itself takes no institutional policy positions. The IZA research network is committed to the IZA Guiding Principles of Research Integrity.

The Institute for the Study of Labor (IZA) in Bonn is a local and virtual international research center and a place of communication between science, politics and business. IZA is an independent nonprofit organization supported by Deutsche Post Foundation. The center is associated with the University of Bonn and offers a stimulating research environment through its international network, workshops and conferences, data service, project support, research visits and doctoral program. IZA engages in (i) original and internationally competitive research in all fields of labor economics, (ii) development of policy concepts, and (iii) dissemination of research results and concepts to the interested public.

IZA Discussion Papers often represent preliminary work and are circulated to encourage discussion. Citation of such a paper should account for its provisional character. A revised version may be available directly from the author. 


\section{ABSTRACT}

\section{Tattoos, Life Style and the Labor Market ${ }^{*}$}

Placing a tattoo is a choice with potentially significant and long-lasting social and economic consequences. In this study we look at the factors determining the decision to place a tattoo and combine this with several outcomes, such as income and employment status, living together with a partner, (perceived) health and substance use. The analyses are based on unique panel data of a representative sample of Dutch individuals. The tattooed population differs significantly from the non-tattooed population on a wide range of characteristics. The first part of our analysis describes the number, timing, location, size and visibility of tattoos. In the second part we use fixed effects and instrumental variables analysis to explore the effect of tattoos on the above mentioned outcome measures. Our analyses suggest less favorable outcomes for people with (very visible) tattoos, though especially in the case of the labor market, the relationships are relatively weak.

JEL Classification: J10, J20

Keywords: tattoos, labor market, health, family, panel data

Corresponding author:

Rik Dillingh

Department of Economics

Tilburg University

PO Box 90153

5000 LE Tilburg

The Netherlands

E-mail: w.f.dillingh@uvt.nl

\footnotetext{
* The authors would like to thank Nynke de Groot, Mauro Mastrogiacomo, Arthur van Soest, Marike Knoef, Ben Vollaard, Iris Kooreman, the participants of the $29^{\text {th }}$ Annual Conference of the European Society for Population Economics (ESPE) on June 18, 2015 in Izmir and the participants of the LaborHealth Seminar on September 9, 2014 at Tilburg University for valuable comments and suggestions and Joris Mulder and Miquelle Marchand from CentERdata and Thijs Veenstra from RIVM for their help with the data collection. The LISS panel data used in this study were collected by CentERdata (Tilburg University, The Netherlands) through its MESS project funded by the Netherlands Organization for Scientific Research.
} 


\section{Introduction}

Various aspects of physical appearance - both objective characteristics like height and more subjective characteristics such as beauty - have been shown to influence labor market outcomes (Hamermesh and Biddle, 1994; Watkins and Johnston, 2000; Harper, 2000). A person's natural features and the way he or she is clothed and groomed can have an effect on hiring, firing and promoting decisions of employers, possibly through direct preferences or through an (assumed) relationship with productivity. Natural features like height and beauty are largely exogenous and can only be changed to a certain extent and/or at high costs. One’s clothing style, on the other hand, can be changed radically overnight and can be used as an identity signaling device.

A specific example of identity signaling is placing a tattoo (Akerlof and Kranton, 2000; Fryer and Jackson, 2008). A tattoo is a permanent ink decoration on the skin. Techniques for removing tattoos have substantially improved, but even with the latest laser treatments the procedure is still painful, costly and not always (completely) successful. This means most people effectively make a life time decision when they choose to have a tattoo. Tattoos are widespread and growing in number, yet still controversial. Between 10 and 20 percent of the American population is estimated to have a tattoo - with peaks up to 40 percent of those in their thirties - increasingly including mainstream, middle class individuals (Roberts, 2012; Brallier et al., 2011). For specific, potentially influential, subgroups these percentages can be much higher still. For example, the overall tattoo percentage of NBA players has been over fifty percent every season in the period 2010-2014 ("NBA Tattoos", 2015).

By marking their skin, the tattooed actively identify and position themselves in a particular way, privately and/or publicly, depending on the visibility of their tattoo. This is a 
choice with potentially significant economic and social consequences. Despite the fact that tattoos seem to become more and more common, a tattoo remains a justified reason in the eye of large parts of society, including people in supervisory roles, for being denied employment (e.g. Bekhor et al, 1995; Brallier et al., 2011). Doleac and Stein (2013) show that online market outcomes suffer when the seller displays a wrist tattoo. Harger (2014) finds higher recidivism for inmates with visible tattoos, possibly due to worse employment opportunities.

Besides job market perspectives, research has also focused on the potential relationship between tattoos and (mental) health and deviant behavior (Roberts, 2012). For example, Stirn et al. (2006) find that tattooing is significantly correlated with the perception of reduced mental health and both tattooing and body piercing are correlated with significantly increased sensation-seeking behavior. Mocan and Tekin (2006) show that having a permanent tattoo is associated with a higher propensity to commit crime. Putnins (2011) finds significant positive correlations between having a tattoo and aggression and substance use.

In this study we look at the factors determining the decision to place a (visible) tattoo and relate this to several relevant outcomes, such as income and employment status, (perceived) health and substance use. Not all of these relationships are plausibly causal. Some personal characteristics will help explain why someone chooses to place a tattoo and those characteristics are likely to play a role in many other choices and socioeconomic or health outcomes too. A causal relationship between having a (visible) tattoo and certain socioeconomic outcomes is most plausible through the interaction with other people who may have a (dis)taste for it. We will examine these relationships with fixed effects and instrumental variable analyses. However, the distribution of (visible) tattoos is far from random and possible ways to approximate an experiment on this subject quickly run into practical and/or ethical restrictions. This limits the potential for assessing causal effects. 


\section{Data}

The analyses are based on data from a variety of surveys of the Longitudinal Internet Studies for the Social sciences (LISS) panel administered by CentERdata (Tilburg University, The Netherlands). The LISS panel is a representative sample of Dutch individuals. The panel is based on a true probability sample of households drawn from the population register. Households participate in monthly internet surveys. If they could not otherwise participate they are provided with a computer and Internet connection. The panel is in full operation since October 2007. Background variables like age, gender, household composition, education and several income measures are updated at regular time intervals by one member of the household. A longitudinal survey is fielded in the panel every year, covering a large variety of domains including work, education, income, housing, time use, political views, values and personality. The panel also contains a number of separate unique studies on a range of subjects, like measuring disease prevention, time use and consumption, or risk attitudes. This paper combines information from several of these studies (see Appendix 1 for an overview).

For the purpose of this study we developed an extra questionnaire on the prevalence of tattoos and piercings, which was presented to the LISS panel members in May $2013 .{ }^{1}$ We received 5,215 completed questionnaires out of 6,433 (a response of $81.1 \%$ ). ${ }^{2}$ The questions focused on objective characteristics like the number of tattoos, the year of placement,

\footnotetext{
${ }^{1}$ In our questionnaire we also asked whether our respondents had any piercings. Women have (ear) piercings much more often than man, but piercings other than through the ears are relatively rare for both genders. An important difference between tattoos and piercings is that most piercings are relatively easily removed or hidden, if desired. Respondents indicated that almost none of the piercings other than through the ears are normally visible to everyone and cannot be removed or hidden $(\mathrm{N}=17)$. Therefore, we do not include these data in our further analyses.

${ }^{2}$ The non-response was somewhat higher among the young, the higher educated, women, those with a non-western background and those living in the more urban areas.
} 
location, size and visibility. When people indicated to have three or more tattoos, we only collected detailed information on their first and last tattoo.

\section{Descriptive statistics}

Almost $10 \%$ of the panel members indicated having one or more tattoos $(\mathrm{N}=512)$. Figure 1 shows the dispersion of these tattoos over the separate parts of the body. The favorite location for a tattoo is the upper arm (of those individuals with one or more tattoos almost 40 percent has a tattoo on the upper arms), closely followed by the back and/or belly. Because one person can have one or more tattoos spread over more than one part of the body, the total adds up to more than 100 percent.

Figure 1: Location of tattoos, among those with a tattoo $(\mathrm{N}=512)$

Head/face: $7.4 \%$

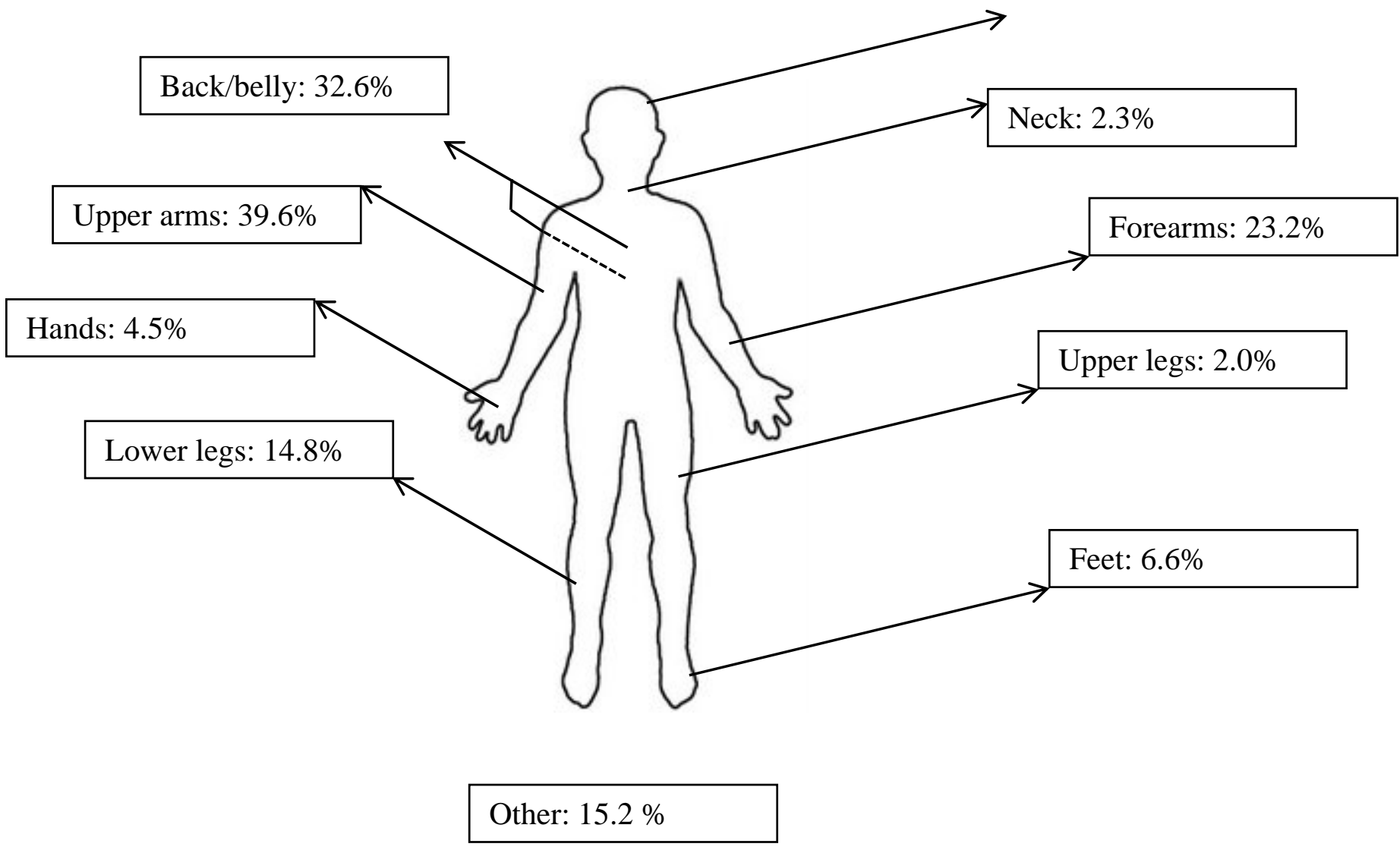

Note: adds up to more than $100 \%$, because a tattoo can cover more than one location 
For several of the potential effects we are interested in, the visibility of the tattoos is a fundamental characteristic. For example, an employer who is considering a job applicant can only take a tattoo into account if he is aware of its existence. Through our questionnaire we gathered information on the subjective visibility of the tattoos for others. We consider tattoos to be subjectively visible when the respondent indicated that 'the tattoo is normally visible to everyone'. The most visible tattoos are those placed on the face, head, neck or hands. We will classify those tattoos as objectively visible. ${ }^{3}$ To correct for the more inconspicuous tattoos, like certain forms of permanent make-up, we subtract those objectively visible tattoos that are not also reported as subjectively visible $(n=8)$. The correlation between the subjectively and objectively visible (type I) tattoos is 0.63 (p-value $<0.0001$ ). Table 1 summarizes the data on visibility level.

Table 1: visibility level

number of persons percentage of tattooed population

\begin{tabular}{lcc}
\hline All tattoos & 512 & $100 \%$ \\
o/w subjectively visible & 146 & $29 \%$ \\
\hline o/w objectively visible ${ }^{a}$ & 59 & $12 \%$ \\
\hline
\end{tabular}

${ }^{a}$ number and percentage cannot be deduced from figure 1, because one person can have tattoos at multiple locations

\footnotetext{
${ }^{3}$ We considered, in accordance with Harger (2014), to differentiate between two levels of objective visibility: 1) tattoos that are visible even when the individual is wearing a suit and 2) tattoos that are visible when employees can wear a T-shirt and/or shorts. Because so many tattoos are placed on arms and legs, we found the second level of objective visibility to be insufficiently discriminating to include it in our analyses.
} 
We also inquired about the size of the tattoos. We define tattoos that cannot be fully covered with one hand as big tattoos. Just over 26\% (134 out of 512) indicate they have one or more big tattoos. This percentage increases from $11 \%$ of people with only one tattoo to over $56 \%$ of people with three or more tattoos. A regression of the number of tattoos on whether or not the first tattoo was big suggests that if the first tattoo is big, there is a (statistically significant) higher chance that more tattoos will follow. Also, later tattoos are more often big tattoos.

Over $40 \%$ of tattoos contain not just black ink but also color(s). About a quarter of the tattoos contains text, often names. Frequently mentioned tattoo images are animals (butterflies), hearts, stars, crosses and tribal or Keltic motives. Many tattoos symbolize themes like love and family, freedom and religion. Several respondents indicate that their tattoo is linked to an important life event, either positive (like the birth of a child) or negative (like the loss of a loved one). Respondents were also asked whether some people could find the text or image of the tattoo offensive to a certain extent. Just over 6\% (33 out of 512) indicate they have a more or less shocking tattoo. This percentage increases from $3 \%$ of people with only one tattoo to almost $13 \%$ of people with three or more tattoos. Later tattoos are more often shocking. 
Because we have information on both the age of our respondents and the year in which they placed their first tattoo, we can make an age-cohort graph of the prevalence of tattoos in our panel. Figure 2 shows that, at all ages, each cohort has more tattoos than the previous cohorts.

Figure 2: age-cohort graph of prevalence of tattoos

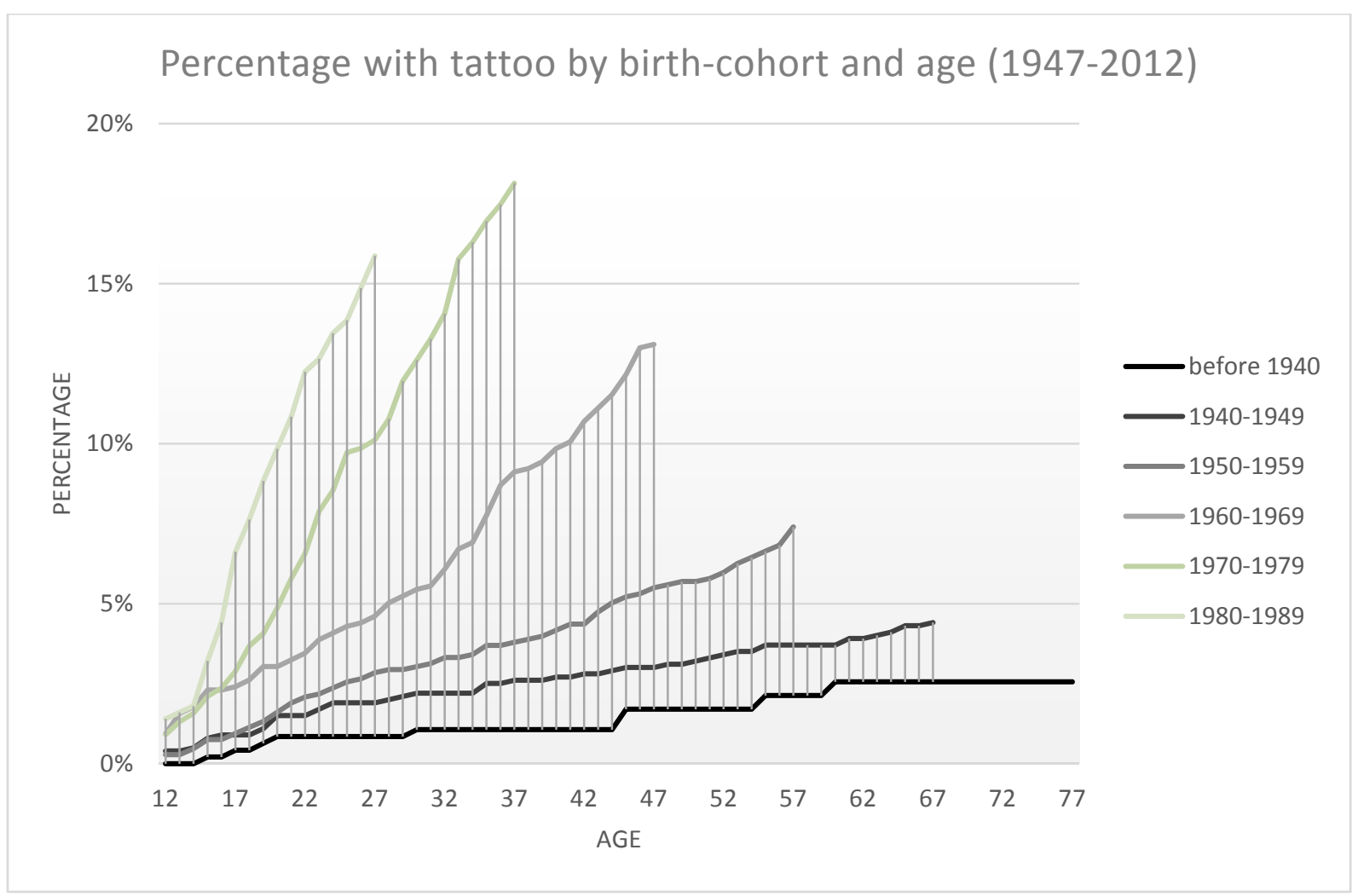


Obviously, the presence of a tattoo is not randomly distributed among the LISS panel. The tattooed population differs significantly from the non-tattooed population on a range of characteristics. Table 2 shows some descriptive statistics for both groups, on the condition that they are either part of the labor force or disabled, so that our labor market analyses are not clouded by e.g. pensioners, housekeepers and students. The table shows that the tattooed population is not only younger on average (as was already indicated by figure 1), but - based on simple two-sided t-tests - also is more often disabled, blue-collar worker and single, has fewer children in the household, is less often homeowner, lives in a more urban area, is lower educated, more often visited a psychiatrist or psychologist during the last 12 months, is more often obese, has a poorer self-assessed health status, more often smokes, used sedatives, soft drugs, XTC or hard drugs last month, felt anxious, down or depressed during the past month and less often felt peaceful or happy during that period, and is more willing to take risks in several domains. Appendix 2 contains a range of additional descriptive statistics on health (table 9) and religion and politics (table 10). These tables confirm that the tattooed population is health-wise at a disadvantage and shows that they are substantially less religious (especially less protestant), less conservative on family and ethical issues, have less confidence in (governmental) institutions, more often vote for populist parties and are less open to immigration. 


\begin{tabular}{|c|c|c|c|c|c|}
\hline \multirow[b]{2}{*}{ Variables } & \multicolumn{2}{|c|}{ Has no tattoos } & \multicolumn{2}{|c|}{ Has tattoo(s) } & \multirow[b]{2}{*}{ t-test sign. ${ }^{\mathrm{A}}$} \\
\hline & Obs & Mean & Obs & Mean & \\
\hline Gross personal income (month) & 2412 & $€ 2,603$ & 357 & $€ 2,411$ & - \\
\hline \multicolumn{6}{|l|}{ Labor force status } \\
\hline - $\quad$ wage-employed $(d)$ & 2560 & 0.78 & 385 & 0.76 & - \\
\hline - $\quad$ in family business $(d)$ & 2560 & 0.02 & 385 & 0.01 & $* *$ \\
\hline - $\quad$ self-employed $(d)$ & 2560 & 0.08 & 385 & 0.06 & - \\
\hline - $\quad$ unemployed (d) & 2560 & 0.05 & 385 & 0.07 & - \\
\hline - $\quad$ disabled $(d)$ & 2560 & 0.06 & 385 & 0.10 & $* * *$ \\
\hline Blue-collar worker (d) & 2347 & 0.20 & 338 & 0.32 & $* * *$ \\
\hline Age & 2560 & 46.30 & 385 & 42.28 & $* * *$ \\
\hline Female (d) & 2560 & 0.50 & 385 & 0.51 & - \\
\hline In relationship $(d)$ & 2445 & 0.82 & 359 & 0.82 & - \\
\hline - $\quad$ o/w cohabiting $(\mathrm{d})$ & 1994 & 0.92 & 294 & 0.88 & $* *$ \\
\hline Number of children in household & 2560 & 1.01 & 385 & 0.90 & $*$ \\
\hline Homeowner (d) & 2560 & 0.79 & 385 & 0.66 & $* * *$ \\
\hline Urban character ( $0=$ not, $4=$ very strongly) & 2549 & 2.00 & 385 & 2.16 & $* *$ \\
\hline Of Dutch origin & 2513 & 0.89 & 377 & 0.86 & - \\
\hline \multicolumn{6}{|l|}{ Highest level of education with diploma } \\
\hline - $\quad$ primary school $(d)$ & 2552 & 0.04 & 384 & 0.07 & $* *$ \\
\hline - $\quad$ intermediate secondary education (d) & 2552 & 0.17 & 384 & 0.33 & $* * *$ \\
\hline - $\quad$ higher secondary education (d) & 2552 & 0.08 & 384 & 0.07 & - \\
\hline - $\quad$ intermediate vocational education (d) & 2552 & 0.29 & 384 & 0.35 & $* *$ \\
\hline - $\quad$ higher vocational education (d) & 2552 & 0.29 & 384 & 0.14 & $* * *$ \\
\hline - university $(d)$ & 2552 & 0.12 & 384 & 0.04 & $* * *$ \\
\hline Visited physician last year (d) & 2278 & 0.63 & 335 & 0.65 & - \\
\hline Visited physician last year (\#) & 2278 & 1.78 & 335 & 1.95 & - \\
\hline Visited psychiatrist or psychologist last year (d) & 2278 & 0.08 & 335 & 0.13 & $* * *$ \\
\hline Visited psychiatrist or psychologist last year (\#) & 2278 & 0.68 & 335 & 1.97 & $* * *$ \\
\hline Height $(\mathrm{cm})$ & 2288 & 175 & 336 & 175 & - \\
\hline Obese (d) & 2284 & 0.13 & 336 & 0.18 & $* *$ \\
\hline Self-assessed health status ( $1=$ poor, $5=$ excellent) & 2290 & 3.15 & 336 & 3.00 & $* * *$ \\
\hline Smoker (d) & 2286 & 0.16 & 335 & 0.38 & $* * *$ \\
\hline Daily drinker (d) & 2286 & 0.12 & 335 & 0.11 & - \\
\hline \multicolumn{6}{|l|}{ Substance use } \\
\hline - $\quad$ sedatives $(d)$ & 2286 & 0.027 & 335 & 0.060 & $* * *$ \\
\hline - $\quad$ soft drugs (d) & 2286 & 0.015 & 335 & 0.078 & $* * *$ \\
\hline - $\quad X T C(d)$ & 2286 & 0.003 & 335 & 0.012 & $* *$ \\
\hline - $\quad$ hallucinogens $(d)$ & 2286 & 0.000 & 335 & 0.000 & - \\
\hline - $\quad$ hard drugs $(d)$ & 2286 & 0.003 & 335 & 0.027 & $* * *$ \\
\hline \multicolumn{6}{|l|}{ Mood (1 = never, $6=$ continuously): } \\
\hline - $\quad$ anxious & 2288 & 1.99 & 336 & 2.14 & $* *$ \\
\hline - down & 2288 & 1.63 & 336 & 1.77 & $* *$ \\
\hline - $\quad$ peaceful & 2288 & 4.23 & 336 & 3.98 & $* * *$ \\
\hline - depressed & 2288 & 2.00 & 336 & 2.13 & $* *$ \\
\hline - happy & 2288 & 4.23 & 336 & 4.10 & $* *$ \\
\hline \multicolumn{6}{|l|}{$\begin{array}{l}\text { Willingness to take risks }(0=\text { highly risk averse, } \\
10=\text { fully prepared to take risks): }\end{array}$} \\
\hline - in general & 899 & 4.88 & 123 & 5.13 & - \\
\hline - $\quad$ in financial matters & 899 & 3.74 & 123 & 4.20 & $* *$ \\
\hline - in your occupation & 899 & 5.30 & 123 & 5.67 & $*$ \\
\hline - $\quad$ during leisure and sport & 899 & 5.91 & 123 & 6.39 & $* *$ \\
\hline
\end{tabular}


Instrumental Variable analysis: The number of licensed tattoo shops in the vicinity

Having a tattoo is likely to be an endogenous explanatory variable in our analyses. We will use both individual fixed effects models and instrumental variables to mitigate the endogeneity problem. As an instrumental variable for placing a tattoo, we will use the number of licensed tattoo shops in the vicinity of the respondent's dwelling. We conjecture that, conditional on neighborhood or district specific fixed effects, the proximity of licensed tattoo shops does not directly affect our outcomes of interest.

As of 2007, each tattoo and/or piercing shop in the Netherlands is required by law to have a license and to conform to rules of hygienic working. Permanent make-up and cosmetic tattoos also fall under the tattoo regulation. It is illegal to apply a tattoo or piercing to anyone below the age of 12 (except for a piercing in the earlobe). Children between the age of 12 and 16 can get a tattoo or piercing, but only with parental consent and in the presence of the parent(s), and placing a tattoo on their head, neck or hands is prohibited. Beyond the age of 16 it is a fully individual choice. A shop that does not abide to these rules can lose its license.

Through the Dutch National Institute for Public Health and the Environment, (RIVM), we collected a complete list of licensed tattoo shops by 6-digit postal code in the Netherlands in the period 2007-2013. We combined this with the 4-digit (district) and 2-digit (region) postal code information of the LISS panel members to determine the number of available licensed tattoo shops in their vicinity over time. Figure 4 shows the distribution of 2-digit postal codes over the Netherlands, and 4-digit codes over Amsterdam. 
Figure 3: distribution of 2-digit (region) and 4-digit (district) postal codes in the

\section{Netherlands}

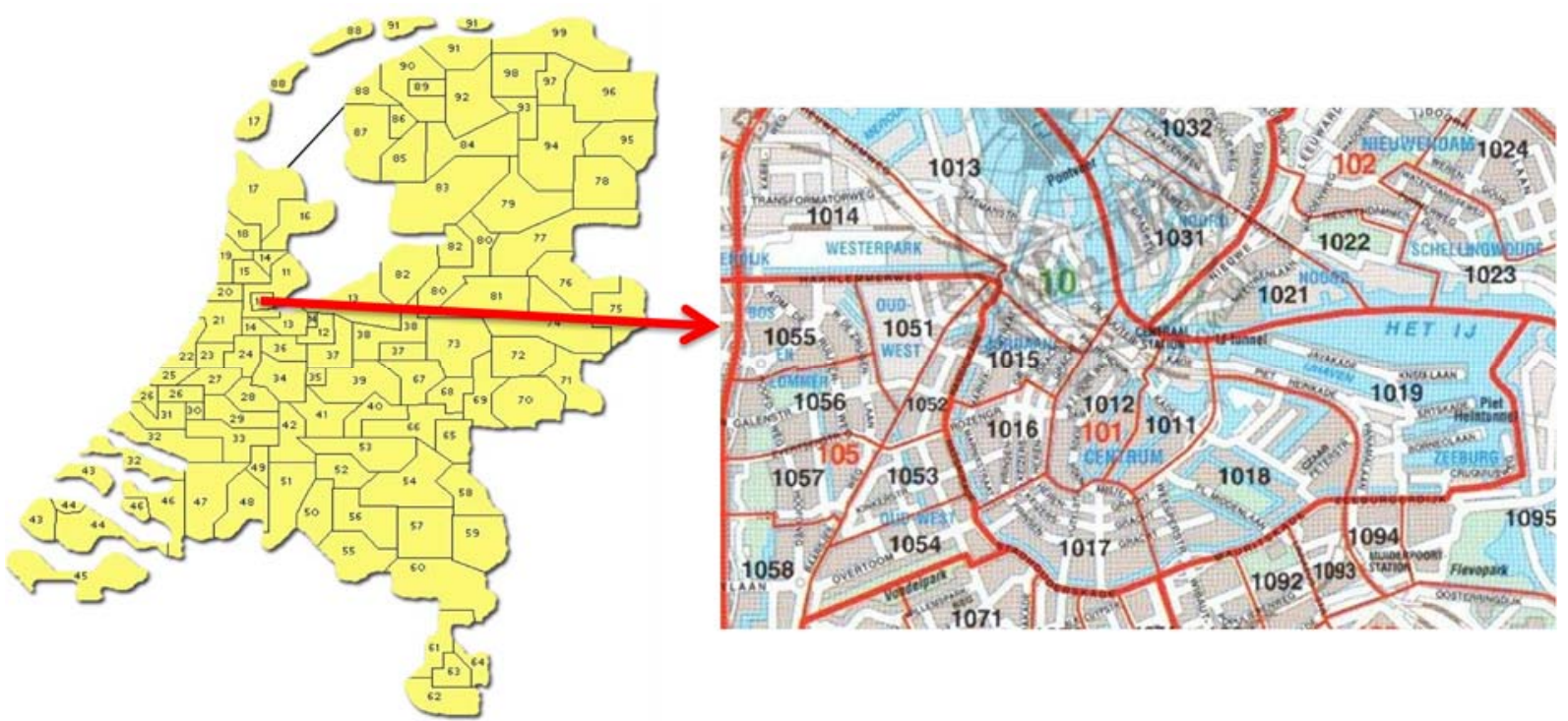

The number of licensed tattoo shops in the Netherlands almost tripled in the period 20072013, from 258 to 744. During this period about 81 percent of our survey sample lived in a district (4-digit postal code) without a licensed tattoo shop and about 1 percent lived in a district with 3 or more of such shops. Almost everyone had at least one shop available in the region (2-digit postal code), with 10 percent having 15 or more shops in the region. 


\section{Empirical results}

We are interested in the potential effects of tattoos on the different domains of life, in particular work, social life and health. We estimate several variations of the following basic model:

$$
\text { Outcome }_{i, t}=f\left(\text { Tattoo }_{i, t}, X_{i, t}^{\prime}\right)+\varepsilon_{i, t}
$$

Here, $i$ refers to the respondent and $t$ to the year of observation.

We consider a selection of outcome measures and three measures for the presence of one or more (visible) tattoos. We make use of a range of control variables $\left(X^{\prime}\right)$, such as age, gender and education. Because our questionnaire on the prevalence of tattoos in the LISS panel was fielded in May, we used as much as possible the observations of all variables in May of each year. Yet, for many variables, including the moment of placement of tattoos, we only have information on the year, not the month. To ensure that the placing of the tattoo precedes the outcome measure we observe, we will also estimate our models with the lagged explanatory variable Tattooj,t-1 (instead of Tattoo $_{j, t}$ ). As discussed in the data section, we focus here on those active on the labor market, to prevent groups like pensioners, students and housekeepers from influencing the results. With this selection we have 381 out of 3,109 individuals left who at some point have at least one tattoo. Of those 381 we observe 53 in our available panel period (2008-2013) before they place their first tattoo.

\section{Having or placing a tattoo}

Table 3 shows the first stage regression results of two standard GLS regression equations, with having a tattoo as the dependent variable and a set of standard independent (control) variables. 
Table 3: Regression results for having or placing a tattoo

\begin{tabular}{|c|c|c|}
\hline & $\begin{array}{l}\text { (1) } \\
R E 2008-2013\end{array}$ & $\begin{array}{l}\text { (2) } \\
F E ~ 2008-2013\end{array}$ \\
\hline \multirow[t]{2}{*}{ Number of licensed tattoo shops in the region } & $0.001 * * *$ & $0.001 * * *$ \\
\hline & $(0.000)$ & $(0.000)$ \\
\hline \multirow[t]{2}{*}{ Age } & $0.011^{* * *}$ & $0.010 * * *$ \\
\hline & $(0.002)$ & $(0.002)$ \\
\hline \multirow[t]{2}{*}{$(\text { Age })^{2}$} & $-0.000 * * *$ & $-0.000 * * *$ \\
\hline & $(0.000)$ & $(0.000)$ \\
\hline \multirow[t]{2}{*}{ Born in 1940-1949 (d) } & 0.027 & 0.000 \\
\hline & $(0.096)$ & (.) \\
\hline \multirow[t]{2}{*}{ Born in 1950-1959 (d) } & 0.068 & 0.000 \\
\hline & $(0.096)$ & (.) \\
\hline \multirow[t]{2}{*}{ Born in 1960-1969 (d) } & 0.149 & 0.000 \\
\hline & $(0.097)$ & (.) \\
\hline \multirow[t]{2}{*}{ Born in $1970-1979(d)$} & $0.241 * *$ & 0.000 \\
\hline & $(0.097)$ & (.) \\
\hline \multirow[t]{2}{*}{ Born in $1980-1989$ (d) } & $0.271 * * *$ & 0.000 \\
\hline & $(0.098)$ & (.) \\
\hline \multirow[t]{2}{*}{ Born after 1990 (d) } & $0.283 * * *$ & 0.000 \\
\hline & $(0.103)$ & (.) \\
\hline \multirow[t]{2}{*}{ Female (d) } & -0.004 & 0.000 \\
\hline & $(0.011)$ & (.) \\
\hline \multirow[t]{2}{*}{ Urban character } & $0.004^{*}$ & 0.002 \\
\hline & $(0.002)$ & $(0.003)$ \\
\hline \multirow[t]{2}{*}{ Of Dutch origin (d) } & -0.019 & 0.000 \\
\hline & $(0.017)$ & (.) \\
\hline \multirow[t]{2}{*}{ Educ(2) - Intermediate secondary (d) } & 0.016 & 0.004 \\
\hline & $(0.010)$ & $(0.011)$ \\
\hline \multirow[t]{2}{*}{ Educ(3) - Higher secondary (d) } & $-0.068 * * *$ & $-0.048 * * *$ \\
\hline & $(0.013)$ & $(0.015)$ \\
\hline \multirow[t]{2}{*}{ Educ(4) - Intermediate vocational (d) } & -0.010 & 0.006 \\
\hline & $(0.011)$ & $(0.012)$ \\
\hline \multirow[t]{2}{*}{ Educ(5) - Higher vocational (d) } & $-0.045^{* * *}$ & 0.004 \\
\hline & $(0.011)$ & $(0.013)$ \\
\hline \multirow[t]{2}{*}{ Educ(6) - University (d) } & $-0.076 * * *$ & -0.021 \\
\hline & $(0.014)$ & $(0.017)$ \\
\hline \multirow[t]{2}{*}{ Constant } & $-0.330 * * *$ & $-0.200 * * *$ \\
\hline & $(0.102)$ & $(0.042)$ \\
\hline R-sqr & 0.042 & 0.005 \\
\hline $\mathrm{N}$ & 3221 & 3221 \\
\hline $\mathrm{NxT}$ & 14609 & 14609 \\
\hline
\end{tabular}

Notes: respondents are part of the labor force or disabled, $(d)=$ dummy variable, $p$-value: $* p<0.10 * * p<0.05$ $* * * p<0.01$

The first column of table 3 contains the results of a random effects analysis over the period 2008-2013. It shows a small, but strongly significant correlation between having a tattoo and our instrument: the number of licensed tattoo shops in the region. The relationship with age is hump shaped, while the 10 year cohort dummies show a strong increase in tattoos over time, as was shown before in figure 3. Gender and being of Dutch origin have no significant 
relationship with having a tattoo, but tattoos are more widespread in the more urban areas. Also, those with a tattoo tend to be lower educated. All these findings are in line with table 2. The second column shows the results of a fixed effects regression over the same period. Most of the control variables are not or only to a certain extent time variant, which considerably limits the potential for significant relationships. Our instrument shows a significant positive relationship with having a tattoo in the FE analysis too.

\section{Work}

As we discussed in the introduction, there are reasons to believe that having one or more (visible) tattoos could have a negative impact on labor market outcomes. In this section we will look at the potential impact of tattoos on income and employment status.

The first indicator we look at is (the log of) gross personal income per month. ${ }^{4}$ Table 4 shows the primary results of $6 \times 3$ separate regression analyses, with the log of gross personal income per month as dependent variable and a dummy for having a tattoo and the control variables shown in table 3 as independent variables. The table only shows the coefficient, standard deviation and significance level of the tattoo variable. Regressions A1-3 show the regressions on having a (visible) tattoo now. Regressions B1-3 show the same analyses, but with a lagged (visible) tattoo variable, to make sure that the income we observe was earned while the tattoo was present.

Out of the 18 regressions shown in table 4, none shows a significant relationship between having a tattoo and earned income. More visible tattoos would be relatively more plausible to have a negative relationship with income, but this is not supported by our data (though the estimates are mostly negative). The coefficients of the IV analyses are very large,

\footnotetext{
${ }^{4}$ To prevent the observations with zero income from dropping out, we add 1 to the income before we take the log of it. Because the information on income was not yet available in 2008, this analysis is based on the period 2009-2013.
} 
but also insignificant. While this might be related to limitations of our instrument variable, it could also merely reflect the absence of causal relationships.

Table 4: Regression results for the log of gross personal income per month

\begin{tabular}{llll}
\hline \hline & RE 2009-2013 & FE 2009-2013 & RE-IV 2009-2013 \\
\cline { 2 - 4 } A1) Has a tattoo & 0.075 & 0.112 & -1.496 \\
& $(0.056)$ & $(0.095)$ & $(1.592)$ \\
A2) Has a subjectively visible tattoo & 0.024 & -0.038 & -7.392 \\
& $(0.096)$ & $(0.132)$ & $(13.056)$ \\
A3) Has an objectively visible tattoo & -0.086 & -0.064 & -6.032 \\
& $(0.157)$ & $(0.229)$ & $(6.990)$ \\
\hline NxT & 11840 & 11840 & 11840 \\
\hline \hline & & & -1.908 \\
B1) Has a tattoo (t-1) & 0.040 & 0.092 & $(1.744)$ \\
& $(0.055)$ & $(0.087)$ & -11.911 \\
B2) Has a subjectively visible tattoo (t-1) & 0.056 & 0.030 & $(14.926)$ \\
& $(0.098)$ & $(0.132)$ & -8.490 \\
B3) Has an objectively visible tattoo (t-1) & -0.052 & -0.059 & $(8.088)$ \\
\hline NxT & $(0.170)$ & $(0.263)$ & 10891 \\
\hline \hline
\end{tabular}

Notes: for the regressions presented in this table, the variables shown in table 3 were used as controls; p-value: $* p<0.10 * * p<0.05 * * * p<0.01$

A (visible) tattoo could also influence one’s employment status. Here, the dependent variable is a dummy, which is 1 if someone is employed (which includes the self-employed) and 0 if someone is unemployed or disabled. Table 5 shows that - in the RE analyses - the chance of being employed is lower for those with a tattoo. The relationship does not hold in the FE analyses. The analyses with a lagged tattoo variable give a comparable picture, though the relationship between unemployment and having a visible tattoo weakens for the RE analyses and turns slightly significant for the FE analysis of all tattoos (B1). Notably, four out of the six IV estimates also turn out to be significant and negative, which supports the relationship we found. Again, though, the IV coefficients are very large, especially for the subjectively visible tattoos. 
Conversely, the chance of being unemployed (not shown) is higher with a (visible) tattoo and the chance of being disabled (not shown) is also higher. Given our data selection everyone must have either one of these three statuses in a particular year. Though placing a tattoo can hardly be considered causal for becoming disabled, it is conceivable that there is some hidden unemployment among the disabled population and that having (visible) tattoos hinders those hidden unemployed from returning to the labor market. The most plausible explanation for a potentially causal relationship between having a (visible) tattoo and not being employed is increased difficulties getting reemployed, because getting fired for placing a tattoo is not likely in view of ensuing employment protection legislation.

Table 5: Regression results for employment status

\begin{tabular}{llll}
\hline \hline & RE 2008-2013 & FE 2008-2013 & RE-IV 2008-2013 \\
\cline { 2 - 4 } A1) Has a tattoo & $-0.038^{* * *}$ & -0.034 & $-1.410^{* *}$ \\
& $(0.013)$ & $(0.021)$ & $(0.660)$ \\
A2) Has a subjectively visible tattoo & $-0.037^{*}$ & 0.003 & -46.434 \\
& $(0.022)$ & $(0.029)$ & $(350.598)$ \\
A3) Has an objectively visible tattoo & $-0.065^{*}$ & -0.027 & $-4.498^{*}$ \\
& $(0.037)$ & $(0.051)$ & $(2.431)$ \\
\hline NxT & 14609 & 14609 \\
\hline \hline & & 14609 & $-1.476^{*}$ \\
B1) Has a tattoo (t-1) & $-0.042^{* * *}$ & $-0.038^{*}$ & $(0.775)$ \\
& $(0.013)$ & $(0.020)$ & 25.049 \\
B2) Has a subjectively visible tattoo (t-1) & -0.038 & 0.006 & $(97.453)$ \\
& $(0.024)$ & $(0.032)$ & $-5.922 *$ \\
B3) Has an objectively visible tattoo (t-1) & -0.063 & -0.021 & $(3.453)$ \\
\hline NxT & $(0.040)$ & $(0.060)$ & 13454 \\
\hline \hline
\end{tabular}

Notes: for the regressions presented in this table, the variables shown in table 3 were used as controls; p-value: $* p<0.10 * * p<0.05 * * * p<0.01$ 


\section{Social life}

In the Data section we found that the chance of being in a relationship is the same for those with and without a tattoo, but that the chance of living together with this partner is significantly lower for those who have a tattoo. Table 6 confirms that for those with a partner there is a significant negative relationship between having a (visible) tattoo and cohabiting, both in the RE and the FE regression specifications. The negative correlation seems to increase with the visibility of the tattoo. While five out of the six IV estimates in table 6 are also negative, none of them is significantly different from 0.

Our data suggest that this result is largely driven by the higher volatility in the relationship status of those with a tattoo. They are more often formally divorced, or married for a second time. They start living together much sooner in their relationship, but also run a higher chance to break up. Overall, this makes observing cohabitation less likely.

The FE regressions would suggest that placing a tattoo negatively influences the chance to cohabit. But in this case it seems more plausible that having a tattoo and cohabiting are both (partly) caused by a third variable, such as a personality trait. Possibly, choosing to have a tattoo coincides with higher levels of impulsivity or time preference (Camerer et al., 2005; Greif et al., 1999). 
Table 6: Regression results for cohabitation status of those with a partner

\begin{tabular}{llll}
\hline \hline & RE 2008-2013 & FE 2008-2013 & RE-IV 2008-2013 \\
\cline { 2 - 4 } A1) Has a tattoo & $-0.040^{* * *}$ & $-0.040^{* *}$ & -0.107 \\
& $(0.013)$ & $(0.020)$ & $(0.485)$ \\
A2) Has a subjectively visible tattoo & $-0.053^{* *}$ & -0.041 & -0.593 \\
& $(0.021)$ & $(0.026)$ & $(4.847)$ \\
A3) Has an objectively visible tattoo & $-0.127^{* * *}$ & $-0.098^{* *}$ & -0.457 \\
& $(0.035)$ & $(0.044)$ & $(1.678)$ \\
\hline NxT & 11255 & 11255 & 11255 \\
\hline \hline & & & 0.044 \\
B1) Has a tattoo (t-1) & $-0.034^{* * *}$ & -0.024 & $(0.680)$ \\
& $(0.013)$ & $(0.020)$ & -0.200 \\
B2) Has a subjectively visible tattoo (t-1) & $-0.075^{* * *}$ & $-0.069 * *$ & $(4.783)$ \\
& $(0.022)$ & $(0.028)$ & -0.117 \\
B3) Has an objectively visible tattoo (t-1) & $-0.163^{* * *}$ & $-0.141^{* * *}$ & $(1.649)$ \\
\hline NxT & $(0.038)$ & $(0.049)$ & 10427 \\
\hline \hline
\end{tabular}

Notes: for the regressions presented in this table, the variables shown in table 3 were used as controls; p-value: $* p<0.10 * * p<0.05 * * * p<0.01$

\section{Health}

Having or placing a tattoo can also impact personal wellbeing. Table 2 already showed that people with a tattoo on average score less favorably on self-assessed health status. Table 7 dives deeper into this relationship. The RE results confirm this previously found negative relationship, but the FE results suggest a more subtle story. Normally, placing a tattoo would be a positive choice by someone who anticipates to enjoy the purchase. The significant positive FE result for a subjectively visible tattoo could be interpreted in that light as indication of a happy consumer. But in that case, the FE results with a lagged variable would suggest this enthusiasm fades out, while those with an objectively visible tattoo might even have started to regret their choices, possible due to the previously discussed less favorable outcomes in work and social life. Because the lagged variables are on average slightly more significant, reversed causality is less plausible. 
Table 7: Regression results for self-assessed health status

\begin{tabular}{|c|c|c|c|}
\hline & RE 2008-2013 & FE 2008-2013 & RE-IV 2008-2013 \\
\hline A1) Has a tattoo & $\begin{array}{l}-0.082^{* *} \\
(0.032)\end{array}$ & $\begin{array}{l}0.080 \\
(0.064)\end{array}$ & $\begin{array}{l}-0.581 \\
(1.501)\end{array}$ \\
\hline A2) Has a subjectively visible tattoo & $\begin{array}{l}-0.026 \\
(0.056)\end{array}$ & $\begin{array}{l}0.174 * * \\
(0.086)\end{array}$ & $\begin{array}{l}-5.658 \\
(8.638)\end{array}$ \\
\hline A3) Has an objectively visible tattoo & $\begin{array}{l}-0.159 * \\
(0.093)\end{array}$ & $\begin{array}{l}-0.167 \\
(0.155)\end{array}$ & $\begin{array}{l}0.830 \\
(5.834)\end{array}$ \\
\hline NxT & 13486 & 13486 & 13486 \\
\hline B1) Has a tattoo (t-1) & $\begin{array}{l}-0.083^{* *} \\
(0.032)\end{array}$ & $\begin{array}{l}0.053 \\
(0.061)\end{array}$ & $\begin{array}{l}-0.957 \\
(0.944)\end{array}$ \\
\hline B2) Has a subjectively visible tattoo (t-1) & $\begin{array}{l}-0.103^{*} \\
(0.060)\end{array}$ & $\begin{array}{l}0.027 \\
(0.092)\end{array}$ & $\begin{array}{l}-29.129 \\
(40.550)\end{array}$ \\
\hline B3) Has an objectively visible tattoo (t-1) & $\begin{array}{l}-0.236 * * \\
(0.099)\end{array}$ & $\begin{array}{l}-0.373^{* *} \\
(0.172)\end{array}$ & $\begin{array}{l}-1.818 \\
(4.483)\end{array}$ \\
\hline NxT & 12400 & 12400 & 12400 \\
\hline
\end{tabular}

Notes: for the regressions presented in this table, the variables shown in table 3 were used as controls; p-value: $* p<0.10 * * p<0.05 * * * p<0.01$

Table 2 showed a strong positive correlation between having a tattoo and substance use, in accordance with e.g. Brooks et al. (2003) and Stirn et al. (2006). In table 8 we present the regression results of the number of substances used on having a tattoo, with substance use on a scale from 0 (no substance use) to 5 (five types of substances used over the past month). The RE results show a consistent and strongly significant positive relationship between having a tattoo and substance use, both in current year and in next year. The FE analyses give the same picture, at least for the visible tattoos. Of course, placing a tattoo cannot plausibly cause increased substance use (except, perhaps, for some use of sedatives due to tattoo related physical problems, like infections to the skin). Possibly, there are omitted variables that cause a rising interest in both tattoos and substances. 
Table 8: Regression results for substance use

\begin{tabular}{|c|c|c|c|}
\hline & RE 2008-2013 & FE 2008-2013 & RE-IV 2008-2013 \\
\hline A1) Has a tattoo & $\begin{array}{l}0.099 * * * \\
(0.013)\end{array}$ & $\begin{array}{l}0.038 \\
(0.026)\end{array}$ & $\begin{array}{l}-0.007 \\
(0.484)\end{array}$ \\
\hline A2) Has a subjectively visible tattoo & $\begin{array}{l}0.150 * * * \\
(0.023)\end{array}$ & $\begin{array}{l}0.138 * * * \\
(0.035)\end{array}$ & $\begin{array}{l}0.774 \\
(2.204)\end{array}$ \\
\hline A3) Has an objectively visible tattoo & $\begin{array}{l}0.088 * * \\
(0.038)\end{array}$ & $\begin{array}{l}0.135^{* *} \\
(0.063)\end{array}$ & $\begin{array}{l}-0.896 \\
(2.240)\end{array}$ \\
\hline NxT & 13458 & 13458 & 13458 \\
\hline B1) Has a tattoo (t-1) & $\begin{array}{l}0.099 * * * \\
(0.013)\end{array}$ & $\begin{array}{l}0.031 \\
(0.025)\end{array}$ & $\begin{array}{l}0.051 \\
(0.468)\end{array}$ \\
\hline B2) Has a subjectively visible tattoo (t-1) & $\begin{array}{l}0.178^{* * *} \\
(0.025)\end{array}$ & $\begin{array}{l}0.206 * * * \\
(0.038)\end{array}$ & $\begin{array}{l}3.834 \\
(4.410)\end{array}$ \\
\hline B3) Has an objectively visible tattoo (t-1) & $\begin{array}{l}0.154 * * * \\
(0.041)\end{array}$ & $\begin{array}{l}0.315^{* * * *} \\
(0.070)\end{array}$ & $\begin{array}{l}-0.121 \\
(2.037)\end{array}$ \\
\hline NxT & 12377 & 12377 & 12377 \\
\hline
\end{tabular}

Notes: for the regressions presented in this table, the variables shown in table 3 were used as controls; p-value: $* p<0.10 * * p<0.05 * * * p<0.01$

\section{Conclusion}

In this study we provided unique data on the prevalence of tattoos in the Netherlands. Based on representative panel data, in 2013 almost $10 \%$ of the Dutch population had at least one tattoo and this number has been growing rapidly in recent years. Each cohort surpasses the previous one in getting more tattoos at a younger age. Yet, based on bivariate correlations, the tattooed population still differs significantly from the non-tattooed population on a wide range of demographic characteristics. In particular on health items, both physical and mental, they score less favorable. Having a tattoo is also still correlated with lower educational attainment.

We performed a series of regression analyses to further study the relationship between having a tattoo and several outcome measures. We found no evidence of a (negative) impact of having a tattoo on income, but we did find some indications that the employment status of 
those with a (visible) tattoo is more vulnerable. We also found that someone with a tattoo has a lower chance of living together with a partner, has a lower self-assessed health status (at least in the longer run), and uses substances more often. We discussed the plausibility of causality in these relationships, but must conclude that in most cases more data is required for further research. 


\section{References}

Akerlof, G. A., \& Kranton, R. E. (2000). Economics and identity. Quarterly journal of Economics, 715-753.

Bekhor, P. S., Bekhor, L., \& Gandrabur, M. (1995). Employer attitudes toward persons with visible tattoos. Australasian journal of Dermatology, 36(2), 75-77.

Brallier, S. A., Maguire, K. A., Smith, D. A., \& Palm, L. J. (2011). Visible tattoos and employment in the restaurant service industry. International Journal of Business and Social Science, 2(6), 72-76.

Brooks, T. L., Woods, E. R., Knight, J. R., \& Shrier, L. A. (2003). Body modification and substance use in adolescents: is there a link? Journal of Adolescent Health, 32(1), 4449.

Camerer, C., Loewenstein, G., \& Prelec, D. (2005). Neuroeconomics: How neuroscience can inform economics. Journal of economic Literature, 9-64.

Doleac, J. L., \& Stein, L. C. (2013). The visible hand: Race and online market outcomes. The Economic Journal, 123(572), F469-F492.

Fryer, R., \& Jackson, M. O. (2008). A categorical model of cognition and biased decision making. The BE Journal of Theoretical Economics, 8(1).

Greif, J., Hewitt, W., \& Armstrong, M. L. (1999). Tattooing and body piercing body art practices among college students. Clinical Nursing Research, 8(4), 368-385.

Hamermesh, D. S., \& Biddle, J. E. (1994). Beauty and the Labor Market. The American Economic Review, 84(5), 1174-1194.

Harger, K. R. (2014). Bad Ink: Visible Tattoos and Recidivism. Available at SSRN 2499502.

Harper, B. (2000). Beauty, stature and the labour market: a British cohort study. Oxford Bulletin of Economics and Statistics, 62(s1), 771-800. 
Mocan, H. N., \& Tekin, E. (2006). Guns and Juvenile Crime*. Journal of Law and Economics, 49(2), 507-531.

NBA Tattoos, retrieved from http://nbatattoos.tumblr.com/ (2015, July)

Putnins, A. (2002). Young offenders, tattoos and recidivism. Psychiatry, Psychology and Law, 9(1), 62-68.

Roberts, D. J. (2012). Secret ink: Tattoo's place in contemporary American culture. The Journal of American Culture, 35(2), 153-165.

Stirn, A., Hinz, A., \& Brähler, E. (2006). Prevalence of tattooing and body piercing in Germany and perception of health, mental disorders, and sensation seeking among tattooed and body-pierced individuals. Journal of Psychosomatic Research, 60(5), 531-534.

Watkins, L. M., \& Johnston, L. (2000). Screening job applicants: The impact of physical attractiveness and application quality. International Journal of Selection and Assessment, 8(2), 76-84. 
Appendix 1: LISS panel data - studies and variables used in regression analyses

1 - Background Variables (November 2007 - May 2013)

age, gender, urban character of place of residence, country of origin, education, net household income, primary occupation

2 - Health: LISS Core Study - wave 1 (2007) to wave 7 (2013)

self-assessed health status, substance use

3 - Religion and Ethnicity: LISS Core Study - wave 1 (2008) to wave 6 (2013)

5 - Family and Household: LISS Core Study - wave 1 (2008) to wave 6 (2013) Relationship and cohabitation status

8 - Politics and Values: LISS Core Study - wave 1 (2007) to wave 7 (2013)

49 - Commercial Opportunities (August 2010)

More information about the LISS panel can be found at: www.lissdata.nl. 
Appendix 2: Additional descriptive statistics

Tabel 9 - Health

\begin{tabular}{|c|c|c|c|c|c|}
\hline \multirow[b]{2}{*}{ Variables } & \multicolumn{2}{|c|}{ Has no tattoos } & \multicolumn{2}{|c|}{ Has tattoo(s) } & \multirow[b]{2}{*}{ t-test sign. ${ }^{\mathrm{A}}$} \\
\hline & Obs & Mean & Obs & Mean & \\
\hline \multicolumn{6}{|c|}{$\begin{array}{l}\text { Do physical health or emotional } \\
\text { problems hinder your ...: (1=not at all, } \\
5=\text { =very much) }\end{array}$} \\
\hline - ...daily activities & 2288 & 1.668 & 336 & 1.854 & $* * *$ \\
\hline - $\quad$...social activities & 2288 & 1.596 & 336 & 1.813 & $* * *$ \\
\hline - $\quad$...work & 2288 & 1.750 & 336 & 1.982 & $* * *$ \\
\hline \multicolumn{6}{|c|}{$\begin{array}{l}\text { Do you regularly suffer from: }(1=y e s \text {, } \\
\text { 0=no) }\end{array}$} \\
\hline - $\quad$ pain in back/joints & 2279 & 0.484 & 332 & 0.506 & - \\
\hline - heart & 2279 & 0.033 & 332 & 0.048 & - \\
\hline - breathing & 2279 & 0.057 & 332 & 0.123 & $* * *$ \\
\hline - coughing/flu & 2279 & 0.161 & 332 & 0.214 & $* *$ \\
\hline - $\quad$ stomach & 2279 & 0.135 & 332 & 0.172 & $*$ \\
\hline - headache & 2279 & 0.193 & 332 & 0.259 & $* * *$ \\
\hline - fatigue & 2279 & 0.305 & 332 & 0.383 & $* * *$ \\
\hline - $\quad$ sleeping problems & 2279 & 0.199 & 332 & 0.280 & $* * *$ \\
\hline - $\quad$ other recurrent complaints & 2279 & 0.125 & 332 & 0.145 & - \\
\hline - no recurrent complaints & 2279 & 0.301 & 332 & 0.235 & $* *$ \\
\hline \multicolumn{6}{|c|}{$\begin{array}{l}\text { How many days in the last month were } \\
\text { you unable to work? ( } 1=0 \text { days, } 5=\text { more } \\
\text { than } 10 \text { days })\end{array}$} \\
\hline - unable to work & 2286 & 1.399 & 335 & 1.612 & $* * *$ \\
\hline \multicolumn{6}{|l|}{$\begin{array}{l}\text { Are you at least once a week taking } \\
\text { medicine for: }(1=\text { yes, } 0=\text { no })\end{array}$} \\
\hline - high blood presure & 2285 & 0.073 & 333 & 0.081 & - \\
\hline - $\quad$ high blood cholesterol & 2285 & 0.130 & 333 & 0.096 & $*$ \\
\hline - infarction & 2285 & 0.020 & 333 & 0.021 & - \\
\hline - $\quad$ other heart disease & 2285 & 0.019 & 333 & 0.033 & - \\
\hline - $\quad$ asthma & 2285 & 0.039 & 333 & 0.069 & $* *$ \\
\hline - $\quad$ diabetes & 2285 & 0.029 & 333 & 0.036 & - \\
\hline - joint pain/infection & 2285 & 0.067 & 333 & 0.087 & - \\
\hline - $\quad$ other pains (headache, etc.) & 2285 & 0.100 & 333 & 0.159 & $* * *$ \\
\hline - $\quad$ sleeping problems & 2285 & 0.037 & 333 & 0.075 & $* * *$ \\
\hline - $\quad$ anxiety or depression & 2285 & 0.046 & 333 & 0.072 & $* *$ \\
\hline • $\quad$ osteoporosis (hormonal) & 2285 & 0.004 & 333 & 0.003 & - \\
\hline - $\quad$ osteoporosis (non-hormonal) & 2285 & 0.007 & 333 & 0.012 & - \\
\hline - heartburn & 2285 & 0.069 & 333 & 0.114 & $* * *$ \\
\hline - $\quad$ chronic bronchitis & 2285 & 0.014 & 333 & 0.033 & $* *$ \\
\hline - $\quad$ other complaints/diseases & 2285 & 0.148 & 333 & 0.183 & $*$ \\
\hline - I do not take any medicine & 2285 & 0.579 & 333 & 0.517 & $* *$ \\
\hline
\end{tabular}




\begin{tabular}{|c|c|c|c|c|c|}
\hline \multirow[b]{2}{*}{ Variables } & \multicolumn{2}{|c|}{ Has no tattoos } & \multicolumn{2}{|c|}{ Has tattoo(s) } & \multirow[b]{2}{*}{ t-test sign. ${ }^{\mathrm{A}}$} \\
\hline & Obs & Mean & Obs & Mean & \\
\hline Had religious parents at age 15 (d) & 2416 & 0.644 & 356 & 0.463 & $* * *$ \\
\hline - Had catholic parents at age 15 (d) & 2407 & 0.346 & 354 & 0.271 & $* * *$ \\
\hline - Had protestant parents at age 15 (d) & 2407 & 0.273 & 354 & 0.181 & $* * *$ \\
\hline Is religious $(\mathrm{d})$ & 2411 & 0.340 & 362 & 0.171 & $* * *$ \\
\hline - Is catholic (d) & 2410 & 0.158 & 362 & 0.097 & $* * *$ \\
\hline - Is protestant (d) & 2410 & 0.160 & 362 & 0.058 & $* * *$ \\
\hline Believes in god (0-5 scale) & 2439 & 2.047 & 367 & 1.752 & $* * *$ \\
\hline Believes in afterlife (d) & 2439 & 0.282 & 367 & 0.283 & - \\
\hline Believes in heaven (d) & 2439 & 0.234 & 367 & 0.183 & $* *$ \\
\hline Believes in purgatory (d) & 2439 & 0.038 & 367 & 0.035 & - \\
\hline Believes in hell (d) & 2439 & 0.094 & 367 & 0.049 & $* * *$ \\
\hline Believes in devil (d) & 2439 & 0.114 & 367 & 0.052 & $* * *$ \\
\hline Believes in Adam and Eve (d) & 2439 & 0.230 & 367 & 0.155 & $* * *$ \\
\hline Believes that Bible is god's word (d) & 2439 & 0.265 & 367 & 0.191 & $* * *$ \\
\hline Praying helps (d) & 2439 & 0.313 & 367 & 0.245 & $* * *$ \\
\hline Attents religious gatherings ( $0=$ never, $6=$ every day) & 2426 & 0.904 & 363 & 0.394 & $* * *$ \\
\hline Prays $(0=$ never, $6=$ every day $)$ & 2421 & 1.554 & 363 & 1.044 & $* * *$ \\
\hline Religion is human invention (d) & 2438 & 0.614 & 367 & 0.632 & - \\
\hline Everyone should have the same religion (d) & 2438 & 0.197 & 367 & 0.226 & - \\
\hline Wife should obey husband (d) & 2438 & 0.042 & 367 & 0.030 & - \\
\hline Husband should obey wife (d) & 2438 & 0.044 & 367 & 0.035 & - \\
\hline Woman should marry as virgin (d) & 2438 & 0.056 & 367 & 0.014 & $* * *$ \\
\hline Man should marry as virgin (d) & 2438 & 0.055 & 367 & 0.014 & $* * *$ \\
\hline Pro choice (d) & 2438 & 0.751 & 367 & 0.798 & $* *$ \\
\hline Believes in reincarnation (d) & 2438 & 0.113 & 367 & 0.193 & $* * *$ \\
\hline Believes in karma (d) & 2438 & 0.185 & 367 & 0.297 & $* * *$ \\
\hline Meditates (d) & 2438 & 0.165 & 367 & 0.180 & - \\
\hline Is interested in the news $(0=$ not, $2=$ very $)$ & 2339 & 1.231 & 333 & 1.141 & $* * *$ \\
\hline \multicolumn{6}{|l|}{ Has confidence in institutions (parliament, police, etc., } \\
\hline $9 \times 0-10$ scale) & 2188 & 46.28 & 315 & 38.68 & $* * *$ \\
\hline Has voted recently (d) & 2293 & 0.874 & 328 & 0.796 & $* * *$ \\
\hline Is right wing (0-10 scale) & 2081 & 5.237 & 277 & 5.318 & - \\
\hline Is pro immigrants (5 statements, 5-pts scale) & 2345 & 14.38 & 336 & 13.51 & $* * *$ \\
\hline Has traditional family values (7 statements, 5 -pts scale) & 2345 & 16.41 & 336 & 15.14 & $* * *$ \\
\hline Is satisfied with government actions (0-4) & 2361 & 1.432 & 343 & 1.222 & $* * *$ \\
\hline Would vote populist now (SP, PVV) (d) & 1979 & 0.219 & 289 & 0.391 & $* * *$ \\
\hline Would vote Christian now (CDA, CU, SGP) (d) & 1979 & 0.124 & 289 & 0.021 & $* * *$ \\
\hline Euthanasia should be permitted (0-4) & 2255 & 3.430 & 320 & 3.691 & $* * *$ \\
\hline Differences in income should decrease (0-4) & 2252 & 2.690 & 315 & 2.867 & $* * *$ \\
\hline Immigrants should adapt entirely to Dutch culture (0-4) & 2277 & 2.693 & 321 & 2.953 & $* * *$ \\
\hline European unification should go further (0-4) & 2166 & 1.394 & 301 & 0.977 & $* * *$ \\
\hline
\end{tabular}

